\title{
FATORES QUE AFETAM A FORMAÇÃO DE COR DURANTE ARMAZENAMENTO DE AÇÚCAR CRISTAL BRANCO
}

\author{
A. L. B. ROCHA ${ }^{1}$, R. B. LIMA ${ }^{1}$, J. A. S. SARTORI ${ }^{1}$, N. T. CORREA ${ }^{1}$,A. S. BAPTISTA ${ }^{1}$, F. $^{2}$ \\ I. B. OGANDO ${ }^{1}$, J. L. MANDRO ${ }^{1}$, F. C. TONOLI ${ }^{1}$, N. L. L. BRAGA ${ }^{1}$, C. L. AGUIAR ${ }^{1}$ \\ ${ }^{1}$ Universidade de São Paulo, ESALQ-USP, Departamento de Agroindústria, Alimentos e \\ Nutrição \\ E-mail para contato: ana.laura.rocha@usp.br
}

\begin{abstract}
RESUMO - Dada a relevância do açúcar, um dos principais subprodutos da canade-açúcar para o Brasil, é crescente a realização de trabalhos visando aumentar a eficiência, bem como evitar perdas no processo. No entanto, durante oarmazenamentodo açúcar, é sabido que fatores ambientais (Temperatura, Umidade Relativa, Luz e Tempo) afetam a qualidade do produto final. Nesse contexto, este projeto teve por objetivos avaliar quais fatores sãodeterminantes para acentuar o processo de formação de corICUMSA durante o período de armazenamento de açúcar cristal branco. Os resultados das quantidades de açúcares redutores (AR), açúcares redutores totais (ART) e cor ICUMSA foram avaliados por superfície de respostas. Concluiu-se que houve alterações das quantidades de AR, ART e cor ICUMSA nas amostras de sacarose analisadas em função das variáveis, sendo a Umidade a mais decisiva. Assim, ficou evidente que deve-se evitar tais condições de umidade e temperatura elevadas nos galpões de armazenamento de açúcar, a fim de que se preserve a qualidade do produto, que é altamente perecível.
\end{abstract}

\section{INTRODUÇÃO}

A importância da agroindústria canavieira no Brasil e os derivados deste setor, na balança comercial, especialmente o açúcar, incentivam trabalhos que abordem o desempenho do segmento exportador do país de maneira particular. Tal setor tem participação direta tanto no mercado interno quanto internacional, uma vez que a cana-de-açúcar está entre as principais culturas em termos de área plantada, volume e custo produtivo (Alves e Bacchi, 2004).

No entanto, durante a armazenagem do açúcar, é sabido que diferentes fatores ambientais afetam a qualidade do produto acabado. Dentre os fatores podem ser listados, a Temperatura, Umidade Relativa do ambiente, a presença de Luz no local de estocagem, bem como o Tempo, ou seja, o período que o produto permanece armazenado.

A sacarose é o carboidrato de maior interesse no processamento da cana-de-açúcar, a qual se deseja obter na forma cristalizada, é susceptível a reações importantes por efeito da temperatura, enzimas e microrganismos (Mantelatto, 2005). 
De acordo com Clarke e Legendre (1999), a cor do caldo de cana-de-açúcar e consequentemente do açúcar, tem sua origem em vários compostos, como: flavonóides,compostos fenólicos e pigmento sendo que aqueles que reagem com os açúcares redutores, são os que mais afetam a cor do caldo e diretamente interferem na qualidade do açúcar.A formação de compostos coloridos no processo de produção de açúcar acontece principalmente pela degradação do açúcar (sacarose), e pela formação dos monossacarídeos glicose e frutose (Mónica, 2004).

Quando relacionado às condições inadequadas de armazenamento, a formação de uma coloração mais escura representa ainda uma questão visual que pode influenciar na decisão de compra do consumidor ao optar por um açúcar "mais branco".

Além disso, mudanças no ambiente causam alterações no açúcar, pois o mesmoabsorve e/ou libera umidade para manter o equilíbrio, sendo que essa umidade dissolve uma pequena quantidade de açúcar a partir das faces cristalinas. Já quando há diminuição da umidade, o açúcar fica duro devido à evaporação da água e recristalização do açúcar. O ponto de contato de dois cristais amplia-se de modoque os cristais se unem. Cada vez que ocorre esse processo, o açúcar torna-se uma "massa dura", comprometendo significativamente a qualidade do produto.

Nesse contexto, a execução do presente projeto de pesquisa teve por objetivos avaliar quais são os fatores determinantes que acentuam o processo de formação de cor durante o período de armazenamento de açúcar cristal branco e qual a interação entre as mesmas, possibilitando conhecimento para adequar os armazéns utilizados atualmente de forma a manter a qualidade do produto.

\section{MATERIAL E MÉTODOS}

Os experimentos foram realizados no laboratório de Açúcar e Álcool do Departamento de Agroindústria, Alimentos e Nutrição (LAN/ESALQ/USP) e utilizadas amostras de sacarose com alto grau de pureza(> 99\%).

Para o delineamento experimental foi utilizado um planejamento fatorial completo $2^{\wedge} 3$, com 3 repetições no ponto central, perfazendo 11 ensaios experimentais. Os resultados foram avaliados por superfície de respostas, donde se analisou os fatores com maior influência na formação de cor ICUMSA nos cristais,sendo todos os dados analíticos avaliados em pacote estatístico Statsoft (2001), além dos dados terem sido submetidos à análise de variância (ANOVA) pelo teste $\mathrm{F}$ e suas médias comparadas no teste de Tukey a $5 \%$ de probabilidade $(\mathrm{p}<0,05)$.

As amostras foram acondicionadas em dessecadores hermeticamente fechados com atmosfera modificada, onde controlou-se a Umidade Relativa dentro do recipiente através de soluções saturadas de Cloreto de Magnésio $\left(\mathrm{MgCl}_{2} \cdot 6 \mathrm{H}_{2} \mathrm{O}\right)$, para obtenção de umidade igual a $30 \%$, Nitrato de Magnésio $\left(\mathrm{MgN}_{2} \mathrm{O}_{6} \cdot 6 \mathrm{H}_{2} 0\right)$ para elaboração de umidade igual a $50 \%$ e Cloreto de Sódio $(\mathrm{NaCl})$ para obtenção de umidade igual a 70\%, (Rockland,1960). 
$\mathrm{O}$ conjunto montado foi levado àestufa com temperatura controlada de $30^{\circ} \mathrm{C}, 40^{\circ} \mathrm{C}$ e $50^{\circ} \mathrm{C}$, por 6 horas, 12 horas e 24 horas para que se realizasse o acompanhamento dos fatores que potencialmente afetam a formação de cor ICUMSA em cristais de açúcar branco durante armazenamento, sendo os fatores estudados: temperatura e umidade relativa, ambos fatores associados a intervalos crescentes de tempo.

\subsection{Parâmetros avaliados:}

- Açúcares redutores: foi utilizado o método de determinação colorimétrica de Somogy-Nelson (Nelson, 1960), no qual foi realizada a leitura de transmitância (T\%) no comprimento de onda de 520nm em espectrofotômetro.

Os teores de açúcares redutores $\left(\mathrm{mgg}^{-1}\right)$ foram calculados pela equação da curva padrão de glicose, segundo a equação abaixo:

$$
A r=\frac{\left[\frac{(T \%+0,015)}{0,043}\right]}{0,00157}
$$

Onde:

$\mathrm{T} \%=$ transmitância da amostra lida.

- Açúcares redutores totais:foi utilizado o método de determinação colorimétrica de Somogy-Nelson (Nelson, 1960), no qual foi realizada a leitura de transmitância (T\%) no comprimento de onda de $520 \mathrm{~nm}$ em espectrofotômetro.

Os teores de açúcares redutores $\left(\mathrm{mgg}^{-1}\right)$ foram calculados pela equação da curva padrão de glicose, segundo a equação abaixo:

$$
A R T=\frac{\left[\left(\frac{T \%+0,015}{0,043} * 20\right)\right]}{0,00157}
$$

Onde:

$\mathrm{T} \%=$ transmitância da amostra lida.

- Cor ICUMSA: foi utilizado o método descrito por Lopes, 1985 do Manual de Métodos de Análise de Açúcar, no qual as amostras foram lidas em espectrofotômetro nos comprimentos de ondas de $420 \mathrm{~nm}$. Utilizou-se água destilada para aferir o aparelho. $O$ índice de cor foi calculado segundo a equação abaixo:

$$
\operatorname{Cor}=\frac{1000(-\log T)}{\mathrm{bc}}
$$

$\mathrm{T}=$ transmitância da solução, em porcentagem;

$\mathrm{b}=$ medida da lente da cubeta $(\mathrm{cm})$;

$\mathrm{c}=$ concentração da solução $(\mathrm{g} / \mathrm{ml})$; 


\section{RESULTADOS}

Através da análise da Figura 1 (a), é possível inferir que há um progressivo aumento nos teores de $\mathrm{AR}$ à medida que a temperatura se eleva. Isso pode estar relacionado a um favorecimento ocasionado pela temperatura, o que contribuiu para o processo de inversão da sacarose, originando glicose e frutose.

(a)

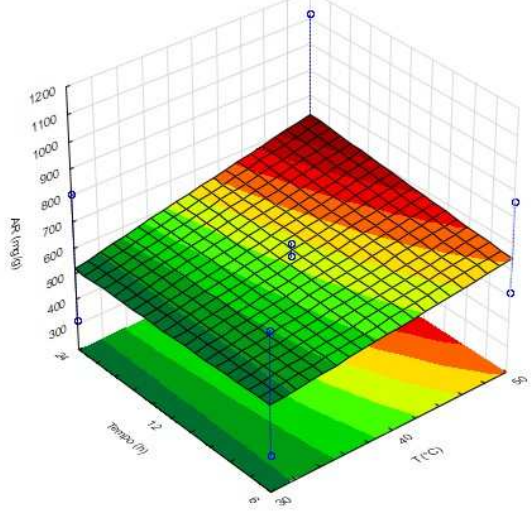

(b)

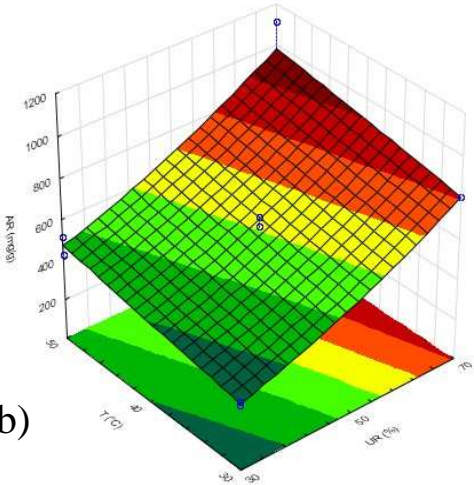

Figura 1 - Superfície de resposta gerada para a interação das variáveis x2: temperatura $\left({ }^{\circ} \mathrm{C}\right) \mathrm{e}$ x3 tempo (h) para obtenção dos valores de açúcares redutores (AR) $\left(\mathrm{mg} \mathrm{g}^{-1}\right)$ (a) e superfície de resposta gerada para a interação das variáveis $\times 1$ : umidade relativa (\%) e x2: temperatura $\left({ }^{\circ} \mathrm{C}\right)$ para obtenção dos valores de açúcares redutores $(\mathrm{AR})\left(\mathrm{mg} \mathrm{g}^{-1}\right)(\mathrm{b})$.

Ao se fundir, a sacarose perde água e se transforma nos anidridos de glicose e de frutose ou glicosanos e levulosanos. A reação é autocatalisada, pois a água formada acelera a reação. Os anidridos formados se combinam com a água e produzem ácidos derivados que hidrolisam a sacarose remanescente, produzindo glicose e frutose. Os levulosanos e glucosanos formados também podem combinar-se com a água e reaparecer a frutose e a glicose. (Oetterer et. al., 2006).

Rodrigues et al. (2000) em estudos de hidrólise catalítica da sacarose, verificaram que o fator com maior influência foi a temperatura, uma vez que seu aumento foi diretamente proporcional à taxa de inversão do xarope de sacarose.

A análise da Figura 1 (b) possibilita a verificação de que, conforme há o aumento da Umidade Relativa do recipiente, obteve-se maiores teores de AR, isso por que, conforme mencionado anteriormente, a reação é catalisada conforme maior teor de água disponível no meio. Nesse experimento, os teores de AR aumentaram conforme a variável temperatura também se elevou.

$\mathrm{Na}$ Figura 2, pode-se observar ao fundo a formação de compostos pigmentosos durante o ensaio sob efeito de temperatura e umidade. Conforme descrito por Araújo (1995), açúcares em temperaturas acima de $120^{\circ} \mathrm{C}$ são pirolisados para diversos produtos de degradação de alto peso molecular e escuros denominados caramelos. Essa reação envolve a degradação do açúcar na ausência de aminoácidos ou proteínas. 
Durante todo o tempo da reação ocorrem desidratações e hidrólises, chegando ao final com predominância de ácidos como o acético e o fórmico, de aldeídos como o formaldeído e o hidroxi-metilfurfural, diacetil, carbonilas e grupos enólicos. Estes são compostos responsáveis pelo aroma, porque são voláteis, e pela cor, porque são ativos, recombinam-se e formam o polímero que é um pigmento chamado melanoidina. O processo de caramelização constitui-se de reações autocatalisadas pelo desprendimento de água, aceleradas pelo calor e umidade (Oetterer et. al., 2006).

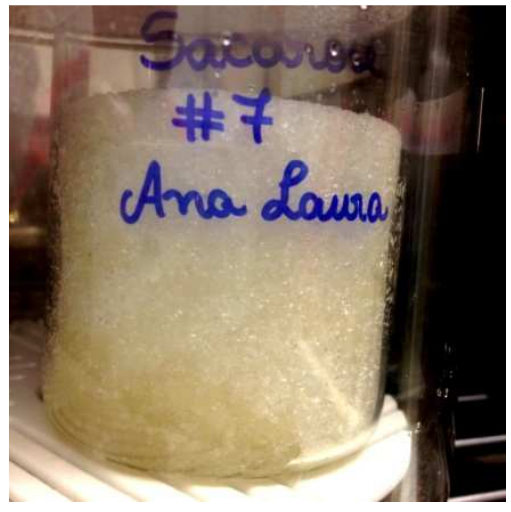

Figura 2 - Formação de compostos pigmentosos durante o ensaio sob efeito de temperatura e umidade.

(a)

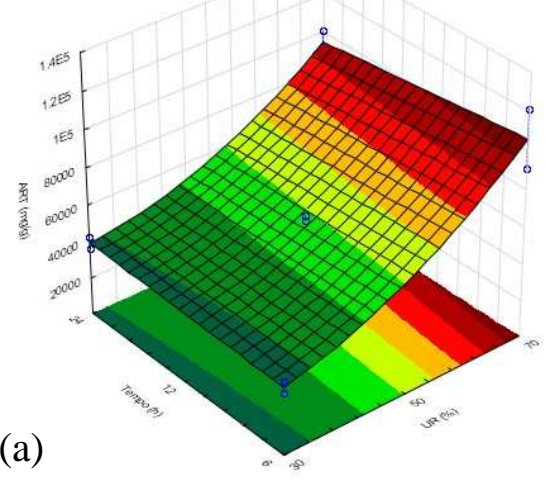

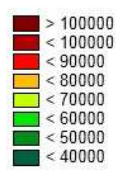

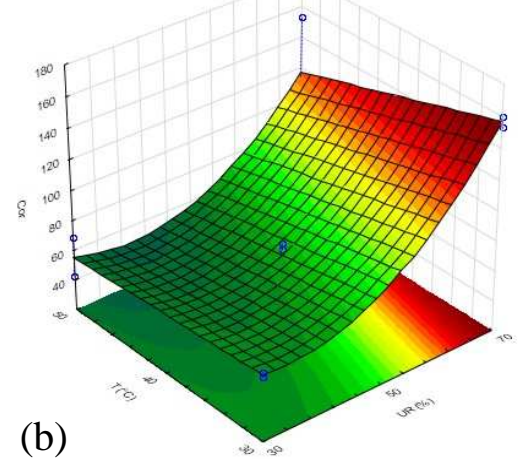

(b)

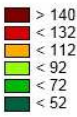

Figura 3 - Superfície de resposta gerada para a interação das variáveis x1: umidade relativa (\%) e x3: tempo (h)para obtenção dos valores deaçúcares redutores totais (ART) $\left(\mathrm{mg} \mathrm{g}^{-1}\right)$ (a) e superfície de resposta gerada para a interação das variáveis x1: umidade relativa (\%) e x2: temperatura $\left({ }^{\circ} \mathrm{C}\right)$ para obtenção dos valores de cor ICUMSA (b).

Analisando-se a figura 3 (a), é possível inferir que, conforme aumentou a Umidade Relativa do meio, obteve-se maiores quantidades de ART formados no final do processo. Isso porque a reação é catalisada pela água disponível no meio. O tempo de duração parece não ter influenciado de forma decisiva nesse aumento.

Avaliando-se a tendência de aumento de cor ICUMSA, verifica-se que em condições de umidade relativa alta, independentemente da temperatura em questão, houve aumento de cor, sendo esse fato indesejado no processo de armazenamento de açúcar. 


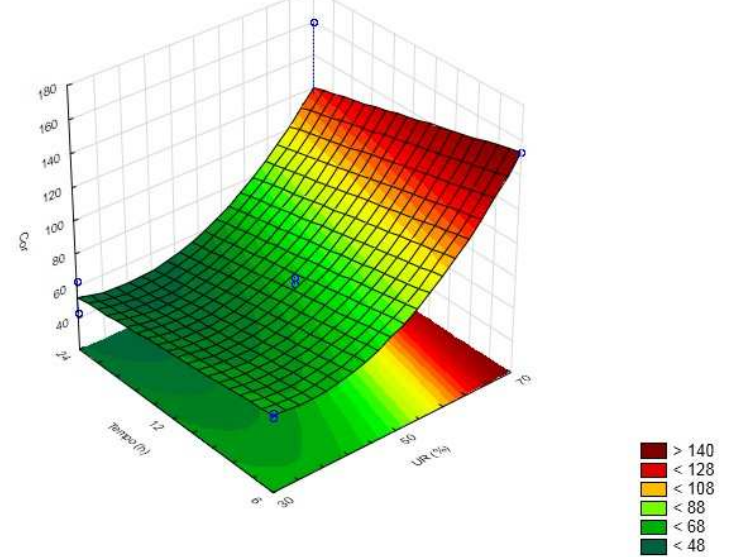

Figura 4 - Superfície de resposta gerada para a interação das variáveis x1: umidade relativa (\%) e x3: tempo (h)para obtenção dos valores de cor ICUMSA.

A Figura 4 apresenta a superfície de resposta para obtenção de cor ICUMSA final para as variáveis UR e tempo. É possível observar que, independente do tempo determinado no planejamento fatorial, a cor ICUMSA foi mais expressiva na umidade relativa máxima utilizada.

\section{DISCUSSÃO}

Através da análise das superfícies de resposta obtidas, pode-se observar uma tendência geral de aumento de cor ICUMSA, AR e ART conforme aumentos progressivos de Umidade Relativa do ambiente, independentemente das temperaturas e tempos empregados.

O aquecimento de carboidratos, em especial de sacarose e de açúcares redutores, na ausência de compostos nitrogenados, dá lugar também à produção de uma série de reações muito complexas, que são conhecidas como caramelização(Fennema, 2000).

A caramelização, segundo Araújo (1995), não requer nem oxigênio nem compostos de nitrogênio, ocorrendo em pH ótimo de 3,0 a 9,0, produzindo caramelo, muito embora os teores de $\mathrm{pH}$ não tenham sido monitorados nesse experimento. Como escurecimento não enzimático pode-se ter também a reação de oxidação de ácido ascórbico que requer oxigênio, porém não requer compostos de nitrogênio, ocorrendo em $\mathrm{pH}$ entre 3,0 e 5,0 com produção de melanoidinas.

O mecanismo dessa reação (caramelização) para Ribeiro e Seravalli (2007), ainda é pouco conhecido. Segundo autoras, sabe-se que o aquecimento provoca a quebra de ligações glicosídicas, quando elas existem como na sacarose, abertura do anel hemiacetálico, formação de novas ligações glicosídicas. Como resultado ocorre a formação de polímeros insaturados, os caramelos.

De maneira mais específica, Evangelista (2005), afirma que o escurecimento que caracteriza a caramelização é conseqüência da reação entre os açúcares chamados polidroxicarbonilados que contêm grupos hidroxilas e grupos carbonilas. Nessa reação que se realiza sob elevadas temperaturas se verifica a desidratação do açúcar e formação de aldeídos 
muito ativos, como o hidroxi-metilfurfural(HMF) responsável pelo odor característico agradável do açúcar caramelizado.

Em geral, as reações de escurecimento são prejudiciais para o valor nutricional do alimento em questão, e podem ocorrer durante o processamento, bem como durante o armazenamento de produtos alimentares. É, portanto, necessário buscar condições para evitar essas reações, assim, não só prevenindo quaisquer alterações nutricionais, mas também outras alterações que possam tornar o alimento inaceitável para o consumidor (Eskinetal.,1971).

Considerando que a previsão de produção de açúcar para a safra 2013/14 é de 38,81 milhões de toneladas (Conab, 2013), fica evidente, que deve-se evitar tais condições de umidade relativa alta, bem como temperaturas elevadas nos galpões de armazenamento de açúcar, a fim de que se preserve a qualidade do produto, que é altamente perecível.

\section{CONCLUSÃO}

Houve alterações das quantidades de açúcares redutores, açúcares redutores totais e cor ICUMSA nas amostras de sacarose analisadas em função de tempo, temperatura e umidade relativa do ambiente. Fica evidente, portanto, que deve-se manter condições adequadas para a armazenagem do açúcar, devido a já mencionada importância econômica de tal produto para o País, onde boa parte do mesmo é destinado à exportação, sendo que em Julho de 2013, foram registrados 2.297.284.842 kg de açúcar exportados, o que representou US\$ 964.275.532 negociados (UNICA, 2013).

\section{REFERÊNCIAS}

ALVES, L.R.A.; BACCHI, M.R.P. Oferta de exportação de açúcar do Brasil. Revista de Economia e Sociologia Rural, v. 42, n 1, 2004.

ARAÚJO, F. A. D. Processo de clarificação do caldo de cana pelo método de bicarbonatação. Revista Ciências \& Tecnologias, n. 6, p.1-5, 2007.

ARAÚJO, J.M.A. Química de alimentos. 2ed.Viçosa: UFV,1995.

CLARKE, M. A.; LEGENDRE, R. B. Qualidade da cana-de-açúcar: Impactos no rendimento do açúcar e fatores da qualidade. STAB, v. 17, n.6, p. 36-40, 1999.

CONAB-Companhia Nacional de Abastecimento Disponível em: << http://www.conab.gov.br/OlalaCMS/uploads/arquivos/13_12_20_10_56_08_boletim_ca na_portugues_-_dez_2013_3o_lev_-_original.pdf $>$. Acessado em: 04/02/2014 .Acompanhamento da Safra Brasileira - Cana-de-açúcar.Dezembro. 2013.

EVANGELISTA, J. Tecnologia de alimentos. 2 ed. SP: Atheneu, 2005. 
ESKIN, N. A. M.; HENDERSON, H. M.; TOWNSEND, R. J. Biochemistry of foods.Academic Press: New York, 1971. 240 p.

FENNEMA, O.R. Química de los Alimentos. 2ed. Zaragoza: AcribiaS.A , 2000.

ICUMSA. Method G. S. 2/3-9. The determinationof white sugar solution colour Official.InternationalComission for UniformMethodsof Sugar Analysis, 1994.

LOPES, C. H. Métodos de análise de açúcar. 2 ed. Rio de Janeiro: MIC. IAA. DAP, 1985. $39 \mathrm{p}$.

MANTELATTO, P. E. Estudo do processo de cristalização de soluções puras de sacarose de cana-de-açúcar por resfriamento. 2005. Dissertação (Mestrado) - Centro de Ciências Exatas e Tecnologia - Universidade Federal de São Carlos, São Carlos.

MÓNICA, C.; GARCÍA, M. T.; GONZÁLEZ G.; MAR P.; JORGE A. GARCÍA, J. A. Study of coloured components formed in sugar beet processing. FoodChemistry. v. 86, p. 421433, 2004.

NELSON, N.A photometric adaptation of Somogyi method for determination of glucose.Journal of Biologic Chemistry, Bethesda, Md, v. 153, n. 2, p. 375-380, Feb. 1960.

OETTERER, M.; REGITANO-D'ARCE, M. A. B.; SPOTO, M. H. F. Fundamentos de ciência e tecnologia de alimentos. Baureri, 2006.

RIBEIRO, E.P. SERAVALLI, E.A.G. Química de alimentos. 2 ed. SP: EdgardBllucher, 2007.

RODRIGUES, M. V. N.; RODRIGUES, R. A. F.; SERRA, G. E.;ANDRIETTA, S. R.; FRANCO, T. T. Produção de xarope de açúcar invertido por hidrólise heterogênea, através de planejamento experimental. Cienc.Tecnol.Aliment.v. 20. p. 103-109. Campinas, 2000.

ROCKLAND, L. B. Saturated salt solutions for static control of relative humidity between $5^{\circ}$ and $40^{\circ}$ C.Analytical Chemistry, v. 32, n. 10, p. 1375-1376, 1960.

STATSOFT.Statistica (data analysis software system), v. 6.2001.

UNICA - União da Indústria de cana-de-açúcar. Disponível em $<<$ http://www.unicadata.com.br/listagem.php?idMn=66 >> Acessado em: 04/02/2014. 